\title{
Response of Spatio-Temporal Differentiation Characteristics of Habitat Quality to Land Surface Temperature in a Fast Urbanized City
}

\author{
Yongge $\mathrm{Hu}^{1,+} \mathbb{C}$, Enkai $\mathrm{Xu}^{1,+}$, Gunwoo Kim ${ }^{2, *}$, Chang Liu ${ }^{1}$ and Guohang Tian ${ }^{1, *}$ \\ 1 Department of Landscape Architecture, College of Landscape Architecture and Art, \\ Henan Agricultural University, Zhengzhou 450002, China; huyonggec@gmail.com (Y.H.); \\ xek1206@henau.edu.cn (E.X.); cliu229@uic.edu (C.L.) \\ 2 Graduate School of Urban Studies, Hanyang University, 222 Wangsimni-ro, Seongdong-gu, \\ Seoul 04763, Korea \\ * Correspondence: gwkim1@hanyang.ac.kr (G.K.); tgh@henau.edu.cn (G.T.); Tel.: +82-2-2220-0274 (G.K.); \\ +86-0371-6355-8098 (G.T.) \\ + These authors contributed to this work equally and should be regarded as co-first authors.
}

check for updates

Citation: Hu, Y.; Xu, E.; Kim, G.; Liu, C.; Tian, G. Response of Spatio-Temporal Differentiation Characteristics of Habitat Quality to Land Surface Temperature in a Fast Urbanized City. Forests 2021, 12, 1668. https://doi.org/10.3390/f12121668

Academic Editor: Elisabetta Salvatori

Received: 1 November 2021

Accepted: 26 November 2021

Published: 30 November 2021

Publisher's Note: MDPI stays neutral with regard to jurisdictional claims in published maps and institutional affiliations.

Copyright: (c) 2021 by the authors Licensee MDPI, Basel, Switzerland. This article is an open access article distributed under the terms and conditions of the Creative Commons Attribution (CC BY) license (https:// creativecommons.org/licenses/by/ $4.0 /)$.

\begin{abstract}
The degradation and loss of global urban habitat and biodiversity have been extensively studied as a global issue. Urban heat islands caused by abnormal land surface temperature (LST) have been shown to be the main reason for this problem. With the accelerated urbanization process and the increasing possibility of abnormal temperatures in Zhengzhou, China, more and more creatures cannot adapt and survive in urban habitats, including humans; therefore, Zhengzhou was selected as the study area. The purpose of this study is to explore the response of urban habitat quality to LST, which provides a basis for the scientific protection of urban habitat and biodiversity in Zhengzhou from the perspective of alleviating heat island effect. We used the InVEST-Habitat Quality model to calculate the urban habitat quality, combined with GIS spatial statistics and bivariate spatial autocorrelation analysis, to explore the response of habitat quality to LST. The results show the following: (1) From 2000 to 2015, the mean value of urban habitat quality gradually decreased from 0.361 to 0.304 , showing a downward trend as a whole. (2) There was an obvious gradient effect between habitat quality and LST. Habitat quality's high values were distributed in the central and northern built-up area and low values were distributed in the high-altitude western forest habitat and northern water habitat. However, the distribution of LST gradient values were opposite to the habitat quality to a great extent. (3) There were four agglomeration types between LST and habitat quality at specific spatial locations: the high-high type was scattered mainly in the western part of the study area and in the northern region; the high-low type was mainly distributed in the densely populated and actively constructed central areas; the low-low type was mainly distributed in the urban-rural intersections and small and medium-sized rural settlements; and the low-high type was mainly distributed in the western mountainous hills and the northern waters.
\end{abstract}

Keywords: urban biodiversity; urban habitat quality; InVEST model; land surface temperature; Moran's I; Zhengzhou

\section{Introduction}

Urban biodiversity is the driving force of sustainable urban development, and it is of great significance for maintaining a balanced, sustainable human settlement environment [1]. Biodiversity loss, habitat degradation, and the urban heat island effect are generally considered to be intertwined urban problems [2]. Urban heat islands have led to continuous changes in urban species abundance, distribution patterns, and energy flow and material cycling; further, some organisms have been forced to migrate or have even become extinct [3-5]. 
Land surface temperature (LST) is an important indicator that reflects the intensity of urban heat islands, and characterizes the energy balance and climate change on the earth's surface [6,7]. It has a significant impact on the migration of surface matter and energy conversion. The use of thermal infrared remote sensing can obtain a wide range of LST information compared with traditional measurement methods. It is fast and convenient and has a large measurement range, continuous information, and so on, which can be used to measure the characteristics of regional climate change [8,9]. Although the land area of physically urbanized cities only accounts for $3 \%$ of the total land surface area of the earth, the ecological footprint of cities is usually hundreds of times their area [10]. The rise in LST caused by urban activities directly impacts the time and energy that a species must invest in maintaining an optimal body temperature [11]. World Cities Report 2020 from UN-Habitat's pointed out that the world will be further urbanized in the next ten years. The proportion of the global urban population will increase from the current $56.2 \%$ to $60.4 \%$ in 2030, which means urban construction activities will be further expanded and the urban LST differentiation may be more prominent.

Habitat quality refers to the ability of a certain space to provide resources and ensure survival and reproduction for species, which can be regarded as an important characterization and reflection of regional biodiversity [12]. The "Global Biodiversity Outlook 5" report (https:/ / www.cbd.int/gbo/, accessed on 11 August 2021) reveals that the vertebrate population has fallen by more than two-thirds on average since 1970, especially in built-up areas outside nature reserves, where the trend of biodiversity loss has not been effectively curbed.

Improving the habitat quality on which organisms depend for survival is a basic way to protect biodiversity [13-15]. Generally, habitat quality decreases with the intensity of human land use $[16,17]$. The higher the habitat quality, the higher the level of biodiversity and the higher the service capacity of the ecosystem. In the 1980s, based on the experimental data of field surveys focusing on the geographical differentiation characteristics of the habitat conditions of species in a specific area, the evaluation results were generally accurate $[18,19]$. However, the operation is complex, the cycle is long, and it is not easy to promote applications and carry out comparative studies.

After the 21st century, as the integration of RS (remote sensing), GIS (geography information systems) and GPS (global positioning systems) becomes stronger, it is possible to quantitatively, visually, and finely analyze and assess the habitat changes in the spatiotemporal scale of large- and medium-scale. At this stage, the research and application of ecological models such as SolVES (Social Values for Ecosystem Services) [20], ARIES (artificial intelligence for ecosystem services) [21], and InVEST (Integrated Valuation of Ecosystem Services and Tradeoffs) have become the most important in the field of urban ecology. Among many research hotspots of ecosystem service assessment, the InVEST model is the most widely used [22,23]. It was jointly developed by Stanford University, The Nature Conservancy (TNC), and the World Wide Fund for Nature (WWF) to evaluate and weigh ecosystem services. Habitat Quality module is based on the principle of habitat stress to quickly assess the quality of regional habitats. The required data can replace complex methods, such as species surveys, because they are easy to obtain and have a wide range of applications.

At present, research on the characteristics of the spatio-temporal differentiation of habitat quality mainly focuses on grassland [24], wetland [25], watershed [26,27], and forest [28] habitats, among others; research on the driving factors of habitat quality mostly focuses on land use change [29,30], landscape pattern [31,32], topography [33], urban expansion [34], road network [35,36], and species invasion [37]. However, there is a lack of research on the response mechanism of urban habitat quality to LST, especially in the open and complex mega-system metropolis. The purpose of this study is to explore the spatio-temporal mechanism of urban habitat for LST, and adjust the LST to improve the quality of urban habitat. Zhengzhou is a typical agglomeration city under the background of urbanization and an important comprehensive hub in central China. The city is currently 
facing stricter resource and environmental restrictions, which have a negative impact on the urban habitat and biodiversity. In view of this, Zhengzhou was selected as the research object. Based on remote sensing and land use data from 2000 to 2015, we assessed the spatio-temporal differentiation characteristics of Zhengzhou's habitat quality using the InVEST-Habitat Quality model. GIS spatial statistics and GeoDa bivariate spatial correlation were used to analyze the response of habitat quality to LST on the urban area. The results were expected to provide data support for biodiversity conservation and land use planning in megacities.

\section{Study Area}

Zhengzhou $\left(34^{\circ} 16^{\prime}-34^{\circ} 58^{\prime} \mathrm{N}, 112^{\circ} 42^{\prime}-114^{\circ} 14^{\prime}\right.$ E), the capital of Henan Province, is located in the central hinterland of China in the eastern section of the Qinling Mountains, the transitional zone between the second-level and the third-level landform steps in China, with a total area of $7576 \mathrm{~km}^{2}$ and a population of more than 12 million (Figure 1). The terrain is high in the southwest and low in the northeast, descending in a stepped manner. From west to east, it gradually transits from middle and low mountains to tectonic denudation hills, loess hills, slope plains, and alluvial plains, forming a relatively complete geomorphic sequence.

(a)

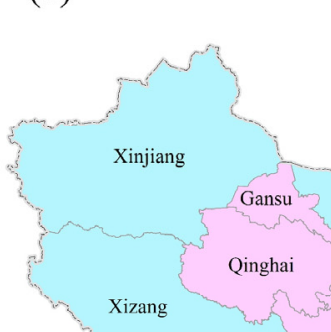

(b)

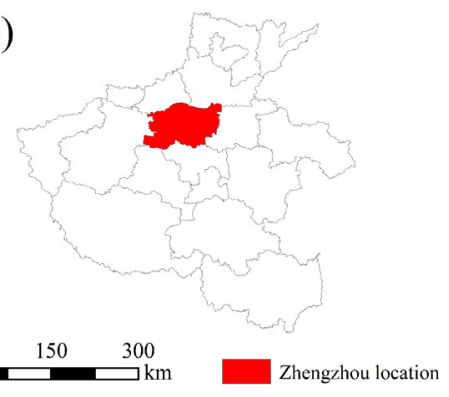

(c)

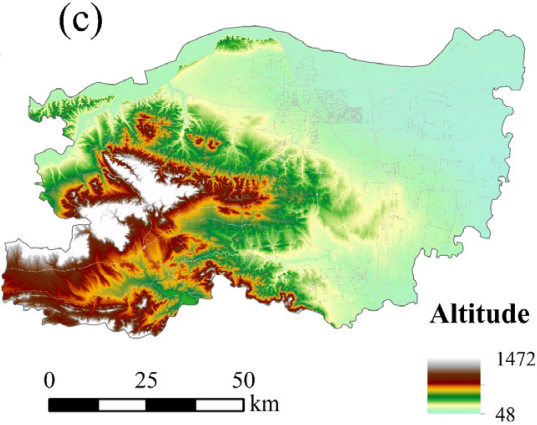

Figure 1. Geographic location (a), administrative district (b), and topography (c) of Zhengzhou region.

The city's main habitats include cultivated land, woodland, grassland, water, construction land, and unused land. Woodland is mainly distributed in the western and southwestern mountains, including Mang Mountain, Song Mountain, Fu Xi Mountain, and Big Bear Mountain, which constitute an ecological barrier in the west of Zhengzhou; the northern Yellow River is the main water area that flows through Zhengzhou, and its banks are located in the middle of the three major migration channels of migratory birds in China. It is an important migratory habitat and wintering place for migratory birds. It is one of the key areas of biodiversity distribution in China and has important ecological value. Cultivated land and grassland are mainly distributed in the southern and eastern plains, and construction land is mainly distributed in the central urban area of Zhengzhou and the built-up areas of cities under its jurisdiction. 


\section{Data Sources and Methods}

\subsection{Data Used}

The workflow steps in our analysis are shown in Figure 2. The principle of the InVESTHabitat Quality model is to combine land-use and land-cover change (LUCC) and threat factors to generate a habitat quality map to reflect the status of regional biodiversity. The interpretation data of land use and cover in 2000, 2005, 2010, and 2015 required to calculate habitat quality are all sourced from the Data Center for Resources and Environmental Sciences, Chinese Academy of Sciences (RESDC) [38,39]. The grid resolution is $30 \mathrm{~m} \times 30 \mathrm{~m}$. The Landsat series of remote sensing images required to retrieve LST are provided by the United States Geological Survey (https: / / earthexplorer.usgs.gov /, accessed on 6 January 2021). To maintain consistency of the data source, images of the same month are selected to minimize the effects of seasonal variation in solar radiation. The dates of the selected images are 8 June 2000 (Landsat 7), 22 June 2005 (Landsat 7), 20 June 2010 (Landsat 7), and 10 June 2015 (Landsat 8). To reduce the difference in topography, illumination, and atmosphere of different time phase images, radiation correction and atmospheric correction were carried out on the four phase images, and the data processing was carried out in ArcGIS 10.2 and ENVI 5.3.

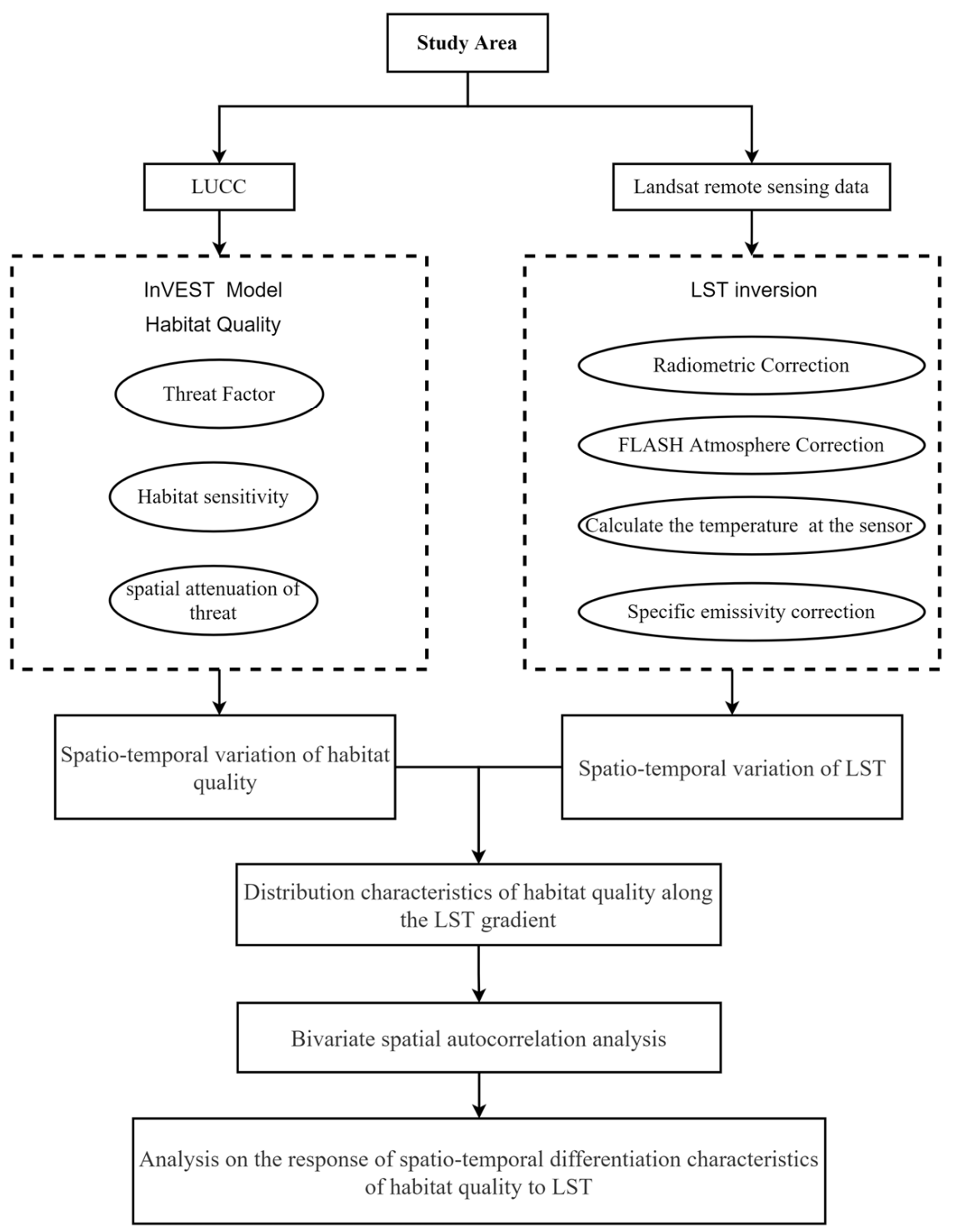

Figure 2. Workflow steps in our analysis. 


\subsection{Habitat Quality Calculation}

The InVEST-Habitat Quality runs using raster data, where each cell in the raster is assigned an LUCC class. The user defines which LUCC types can provide habitat for the conservation objective. Generally, a relative habitat suitability value can be assigned to an LULC type ranging from 0 to 1 . The higher the value, the higher the suitability for the survival and reproduction of individual organisms or populations.

In addition to a map of LUCC and data that relates LUCC to habitat suitability, the model also requires data on habitat threat density and its effects on habitat quality. Each threat source needs to be mapped on a raster grid and all mapped threats should be measured in the same scale and metric. It is worth emphasizing that the impact of threats on habitat in a grid cell is dominated by two main factors. One is the threat sources selected in specific research and their relative impact, the other is the distance between habitat and the threat source and the impact of the threat across space.

Based on the basic situation of the study area, the InVEST User's Guide and previous research results [32,40-43], we defined paddy field, dry land, built-up land, rural residential areas, and other construction land (quarries, mines, traffic land, etc.) as threat sources, and assigned values to the sensitivity of each habitat to threat factors (Tables 1 and 2). The calculation is as follows:

$$
D_{x j}=\sum_{r=1}^{R} \sum_{y=1}^{Y_{r}}\left(\frac{\omega_{r}}{\sum_{r=1}^{R} \omega_{r}}\right) r_{y} i_{r x y} \beta_{x} S_{j r}
$$

Table 1. Habitat types and sensitivity of habitat types to each threat.

\begin{tabular}{|c|c|c|c|c|c|c|c|}
\hline \multicolumn{2}{|c|}{ Habitat Type } & \multirow[b]{2}{*}{$\begin{array}{c}\text { Habitat } \\
\text { Suitability }\end{array}$} & \multicolumn{5}{|c|}{ Threat Factor } \\
\hline Main Category & Subcategory & & $\begin{array}{l}\text { Paddy } \\
\text { Field }\end{array}$ & $\begin{array}{l}\text { Dry } \\
\text { Land }\end{array}$ & $\begin{array}{l}\text { Built-Up } \\
\text { Land }\end{array}$ & $\begin{array}{c}\text { Rural } \\
\text { Residential } \\
\text { Land }\end{array}$ & $\begin{array}{c}\text { Other } \\
\text { Construction } \\
\text { Land }\end{array}$ \\
\hline \multirow{2}{*}{ Cultivated land } & Paddy field & 0.4 & 0 & 1 & 0.5 & 0.3 & 0.4 \\
\hline & Dry land & 0.3 & 1 & 0 & 0.5 & 0.3 & 0.4 \\
\hline & Woodland & 1 & 0.8 & 0.9 & 0.9 & 0.8 & 0.8 \\
\hline \multirow{4}{*}{ Forest } & Shrubwood & 0.7 & 0.4 & 0.5 & 0.6 & 0.4 & 0.5 \\
\hline & Sparse woodland & 0.6 & 0.8 & 0.9 & 0.5 & 0.7 & 0.8 \\
\hline & Other woodland & 0.5 & 0.9 & 1 & 0.5 & 0.7 & 0.8 \\
\hline & High coverage grassland & 0.7 & 0.4 & 0.5 & 0.8 & 0.45 & 0.7 \\
\hline \multirow{2}{*}{ Grassland } & Medium coverage grassland & 0.5 & 0.5 & 0.6 & 0.7 & 0.5 & 0.6 \\
\hline & Low coverage grassland & 0.3 & 0.7 & 0.9 & 0.6 & 0.55 & 0.5 \\
\hline \multirow{4}{*}{ Water } & River and canal & 1 & 0.7 & 0.5 & 0.7 & 0.6 & 0.6 \\
\hline & Lake & 0.9 & 0.7 & 0.5 & 0.7 & 0.6 & 0.6 \\
\hline & Reservoir and pond & 0.8 & 0.8 & 0.4 & 0.8 & 0.7 & 0.7 \\
\hline & Bottomland & 0.6 & 0 & 0 & 0.9 & 0.8 & 0.7 \\
\hline \multirow{3}{*}{ Construction land } & Built-up land & 0 & 0 & 0 & 0 & 0 & 0 \\
\hline & Rural residential land & 0 & 0 & 0 & 0 & 0 & 0 \\
\hline & Other construction land & 0 & 0 & 0 & 0 & 0 & 0 \\
\hline \multirow{5}{*}{ Unused land } & Sandy land & 0.1 & 0.1 & 0.1 & 0.2 & 0.1 & 0.1 \\
\hline & Saline-alkali land & 0.1 & 0.1 & 0.1 & 0.2 & 0.1 & 0.1 \\
\hline & Marshland & 0.6 & 0.5 & 0.6 & 0.8 & 0.6 & 0.5 \\
\hline & Bare soil land & 0 & 0 & 0 & 0 & 0 & 0 \\
\hline & Bare rock land & 0 & 0 & 0 & 0 & 0 & 0 \\
\hline
\end{tabular}

Table 2. Threats' weight and the maximum distance of influence.

\begin{tabular}{cccc}
\hline Threat Source & Relative Weight & Maximum Influence Distance (km) & Spatial Attenuation Function \\
\hline Paddy field & 0.4 & 4 & Exponential \\
Dry land & 0.3 & 4 & Exponential \\
Built-up land & 1 & 8 & Exponential \\
Rural residential land & 0.6 & 6 & Exponential \\
Other construction land & 0.8 & 5 & Exponential \\
\hline
\end{tabular}


In Equation (1), $D_{x j}$ represents the degree of habitat degradation; $R$ represents the total threat sources and $r$ represents one of the threat sources; $y$ represents the grid unit of the $r$ threat layer; $Y_{r}$ refers to the sum of the grids on the $r$ threat layer; $\omega_{r}$ represents the weight of threat source $r ; r_{y}$ is used to judge whether grid $y$ is the source of threat source $r ; \beta_{x}$ represents the protection of society, law, etc., which is not taken into consideration in this research. The accessibility level from threat source $r$ to grid $x, S_{j r}$ represents the sensitivity of habitat type $j$ to threat source $r . i_{r x y}$ represents the distance impact function of threat source $r$ in the habitat of grid $x$ on grid $y$. Assuming that the impact of the threat source on the habitat decays exponentially, the calculation is as follows:

$$
i_{r x y}=\exp \left[1-\left(\frac{2.99}{d_{\text {rmax }}}\right) d_{x y}\right]
$$

In Equation (2), $d_{x y}$ represents the linear distance between grid $x$ and $y$, and $d_{\text {rmax }}$ represents the maximum impact distance of threat source $r$.

Therefore, according to the investment model's calculation principle of habitat quality, the calculation is as follows:

$$
Q_{x j}=H_{j}\left[1-\left(\frac{D_{x j}^{Z}}{D_{x j}^{Z}+k^{Z}}\right)\right]
$$

In Equation (3), $Q_{x j}$ represents habitat quality; $H_{j}$ represents the habitat suitability of land use type $j ; k$ is the half-saturation constant, which is usually set to half of the highest degradation value; $Z$ is the default parameter of the model, $Z=2.5$.

\subsection{LST Inversion Calculation}

As a key parameter in many basic disciplines and applications, LST can provide information about spatio-temporal variation of the surface energy balance. The atmospheric correction method adopted in this study is mainly based on the composition of the thermal radiation intensity observed by the remote sensor on the satellite to calculate LST [44]. The related calculation is as follows:

$$
L=\text { gain } \times D N+\text { bias }
$$

In Equation (4), $L$ is the radiation value of the pixel in the ETM+ thermal infrared band at the sensor, DN is the gray value of the pixel, and gain and bias are the gain and bias values of the thermal infrared band, respectively, which can be obtained from the image header file.

$$
T=K_{2} / \ln \left(K_{1} / L+1\right)
$$

In Equation (5), $T$ is the temperature value at the sensor; $K_{1}$ and $K_{2}$ are calibration parameters, Landsat 7: $K_{1}=666.093 \mathrm{~W} /\left(\mathrm{m}^{2} \cdot \mathrm{sr} \cdot \mu \mathrm{m}\right), K_{2}=1282.710 \mathrm{~K}$; Landsat 8: $K_{1}=774.885 \mathrm{~W} /\left(\mathrm{m}^{2} \cdot \mathrm{sr} \cdot \mu \mathrm{m}\right), K_{2}=1321.079 \mathrm{~K}$. The sensor temperature $(T)$ must be corrected for specific emissivity to estimate the final LST.

$$
\mathrm{LST}=T /[1+(\lambda T / \rho) \ln \varepsilon]
$$

In Equation (6), $\lambda$ is the center wavelength of the ETM+ 6 band $(\lambda=11.335 \mu \mathrm{m})$; $\rho=1.438 \times 10^{-2} \mathrm{~m} \cdot \mathrm{K}$; and $\varepsilon$ is the surface emissivity, which is estimated using the NDVI threshold method [45].

\subsection{Bivariate Moran's I Calculation}

After preliminary analysis, we found that the spatial numerical distribution of habitat quality and LST were very similar, and both had a certain degree of spatial autocorrelation. Bivariate spatial autocorrelation has high applicability and effectiveness in describing the spatial correlation and dependence characteristics of two geographic elements. At present, 
this method has not been found to be used to explore the spatial relationship between habitat quality and LST. Therefore, we have innovatively attempt to adopt this method.

Bivariate Moran's I is an extension and expansion based on Moran's I index, which measures the correlation between the attribute values of spatial units and other attribute values in adjacent spaces $[46,47]$. It can be used as an effective method to analyze the correlation characteristics between urban habitat quality distribution and LST. Bivariate Moran's I is divided into two levels: global Moran's I and local Moran's I. The calculation formula is as follows:

$$
I_{a b}=\left(\frac{X_{m a}-\bar{X}_{a}}{\delta_{a}}\right)\left(\frac{X_{o b}-\bar{X}_{b}}{\delta_{b}}\right) \sum_{j=1}^{n} W_{m o}
$$

In Equation (7), $X_{m a}$ is the value of the variable $a$ of the spatial unit $m, X_{o b}$ is the value of the variable $b$ of the spatial unit $o, \bar{X}_{a}$ and $\bar{X}_{b}$ are the mean values of $a$ and $b$, respectively, and $\delta_{a}$ and $\delta_{b}$ are the variances of $a$ and $b ; W_{m o}$ is the spatial weight matrix between unit $m$ and $o . I_{a b}$ is the Moran's $I$ statistic and its value is between $(-1,1)$ : less than 0 means negative correlation, equal to 0 means no correlation, and greater than 0 means positive correlation. Data processing is done in GeoDa 1.6.7.

\section{Results}

\subsection{Spatio-Temporal Variation of Habitat Quality}

Using the isometric classification method of ArcGIS, the calculation results of habitat quality index were divided into five intervals: $0.00-0.20,0.20-0.40,0.40-0.60,0.60-0.80$, and $0.80-1$, which represent I, II, III, IV, and V (from low to high), respectively. The differences in habitat quality and the evolution law of spatio-temporal pattern in Zhengzhou were further analyzed (Figures 3 and 4).

From the perspective of the time scale, the mean habitat quality of Zhengzhou gradually decreased from 0.361 to 0.304 from 2000 to 2015, with II accounting for the highest proportion of the total area, with an annual mean of $62.94 \%$. Especially, the continuum of habitats located at the intersection of the urban built-up area was gradually fragmented to form scattered and isolated island-like habitats or habitat fragments.
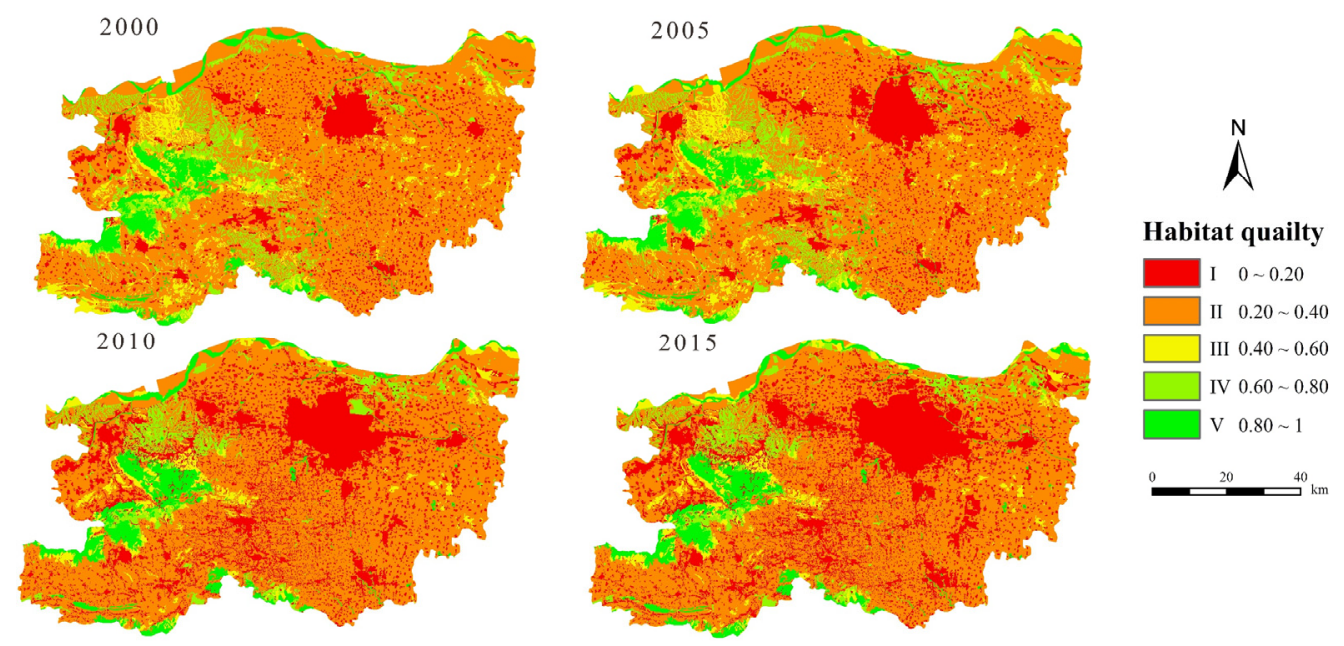

Figure 3. Spatial distribution of habitat quality during the different periods from 2000 to 2015. 


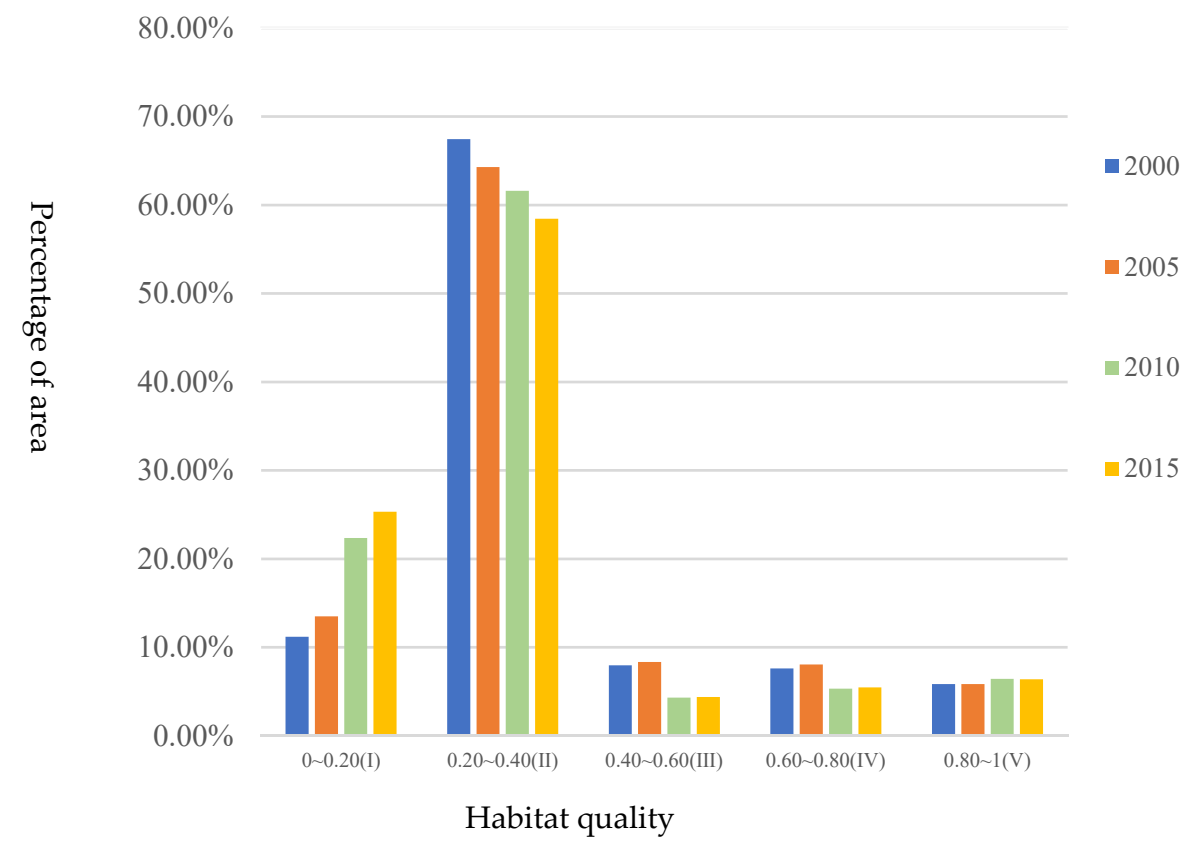

Figure 4. Percentage of the five levels of habitat quality area from 2000 to 2015.

From the perspective of the spatial pattern, the spatial distribution of habitat quality in Zhengzhou is significantly different. II is the most widely distributed, mainly in the low-elevation plains in the east, where human farming is frequent, the ecosystem is single, the vegetation coverage rate is low, and the ecological environment is relatively fragile. I is concentrated in urban built-up areas; the land use structure in these places is dominated by construction land, human activities are disturbed, and biodiversity is low. III, IV, and V are mainly distributed in the high-altitude western mountain and hilly areas, including Fuxi Mountain, Changshou Mountain, Qinglong Mountain, and Song Mountain. These regions have a sparse population with very high green space coverage fraction ratio. Moreover, several ecological protection policies have been implemented, making the habitats there more suitable for many kinds of animals and plants. Further, there are also some IV or higher value habitats in the northern part of the city, thanks to the abundant waters and wetlands-resources suitable for the survival of aquatic animals, plants, and birds.

\subsection{Spatio-Temporal Variation of LST}

To eliminate the influence of dimension and magnitude on the final result, this study uses the range standardization method to process the LST results of Zhengzhou; the value range was $(0,1)$. Using ArcGIS's equal interval classification method, LST was divided into 10 gradients from low to high (Figure 5). In terms of time scale, LST dropped slightly from 2000 to 2005, rose markedly in 2010, and dropped slightly in 2015. The results show that in different stages of Zhengzhou's transformation from traditional industry and agriculture to modern service industry, its overall LST is in a dynamic change process. 

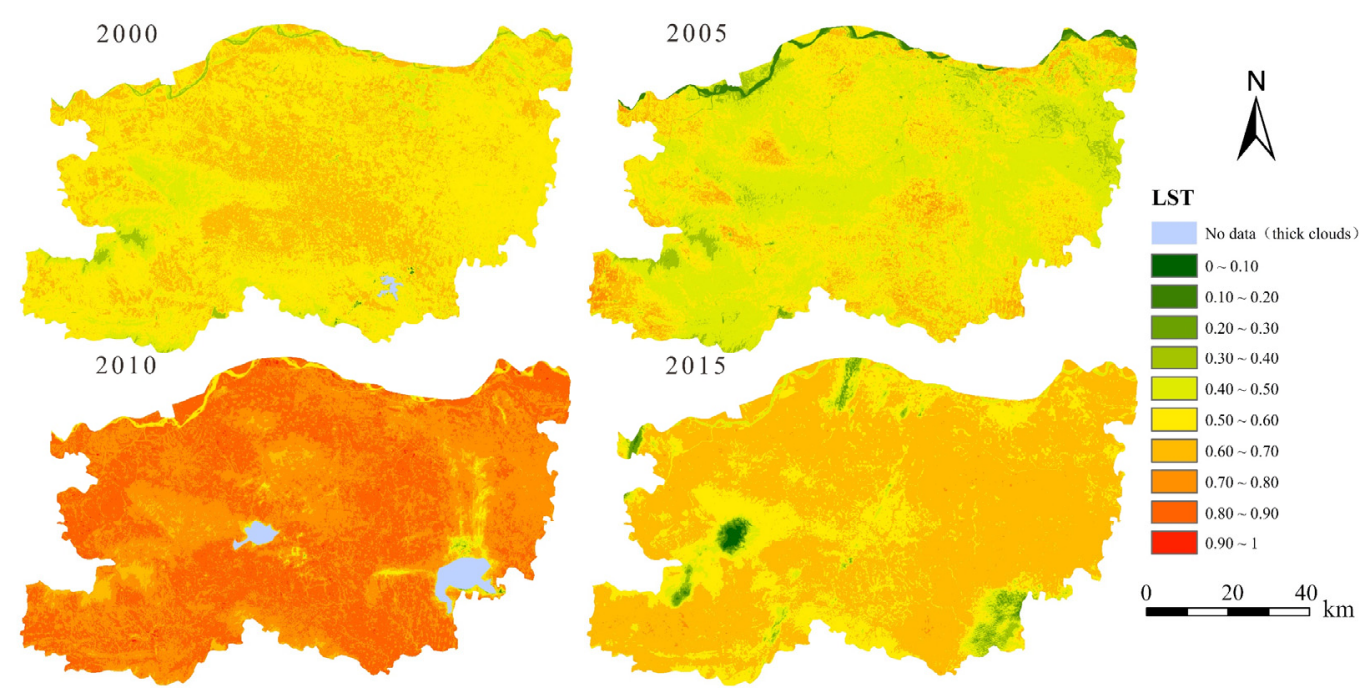

Figure 5. Spatial distribution of LST during the different periods from 2000 to 2015.

From the spatial distribution perspective, high gradients $(8,9,10)$ are distributed in the central city and southern airport area which indicates that the high island effect is mainly affected by human activities; low gradients $(1,2,3,4)$ showed an obvious spatial agglomeration effect in the western mountainous areas and northern waters which indicates that natural habitats have a significant effect on alleviating the heat island effect and are easy to become the center of the cold island effect. The medium gradient $(5,6,7,8)$ is widely distributed in Zhengzhou, indicating that the traditional urban heat island had exceed the boundary of the built-up areas and become a regional heat island.

\subsection{The Distribution of Habitat Quality along LST Gradients}

As seen in Figure 6, there is an apparent numerical gradient effect between habitat quality and LST. From the time scale, the response of habitat quality to LST in the four periods corresponds to four trend lines, which are obviously different. The fluctuation range in 2000 and 2005 is larger than that in 2010 and 2015.

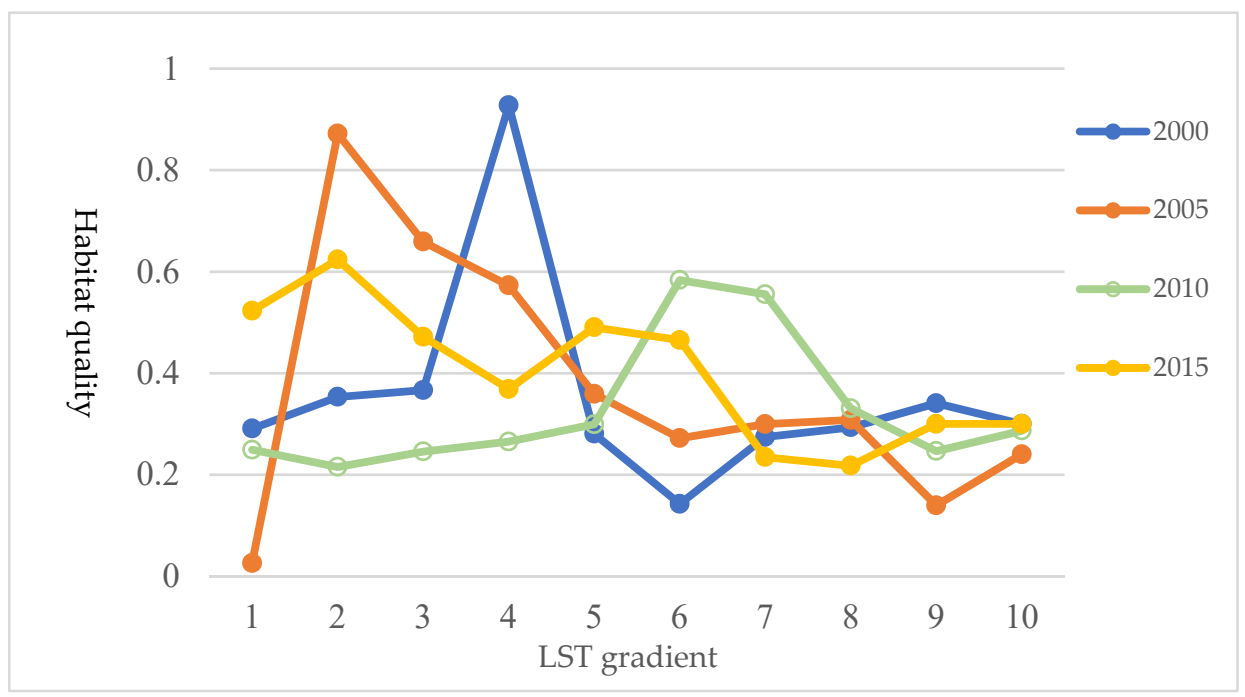

Figure 6. Distribution of habitat quality along LST gradients during the different periods from 2000 to 2015 .

From the perspective of spatial scale, high values of habitat quality are concentrated in low gradients $(1,2,3)$, and low values are concentrated in high gradients $(8,9,10)$, indicating that suitable LST can ensure the stability of habitats. High temperatures can lead 
to restrictive natural factors such as reduced surface runoff, water shortages, and plants' evapotranspiration, which cause a decline in habitat quality and the ability to support biological communities.

\subsection{Bivariate Spatial Autocorrelation Analysis}

Using GeoDa software, the bivariate spatial autocorrelation analysis was carried out with LST as the first variable (X) and habitat quality (HQ) as the second variable (Y). Corresponding to different periods in 2000, 2005, 2010 and 2015, the global Moran's I were $-0.430,-0.313,-0.323$, and -0.311 , respectively (Figure 7). Randomization 999 was selected in GeoDa for the significance test. The results showed that the $p$ values were all 0.001, indicating a significant spatial negative correlation between LST and habitat quality under the confidence of $99.9 \%$; that is, with the increase in LST, habitat quality in Zhengzhou showed a downward trend.

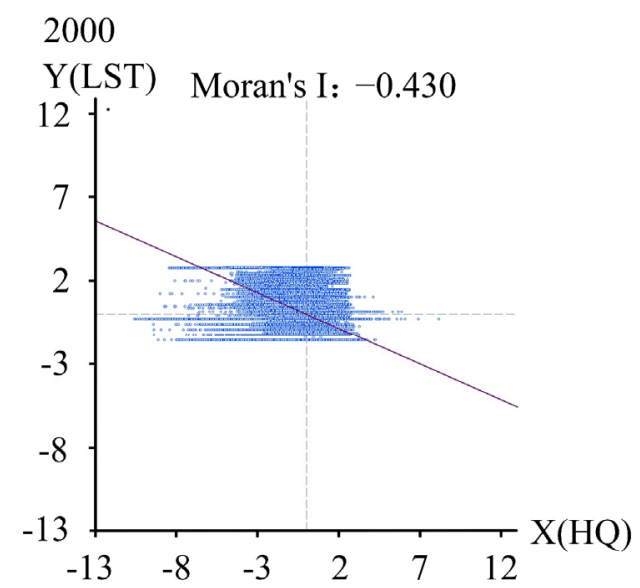

2005

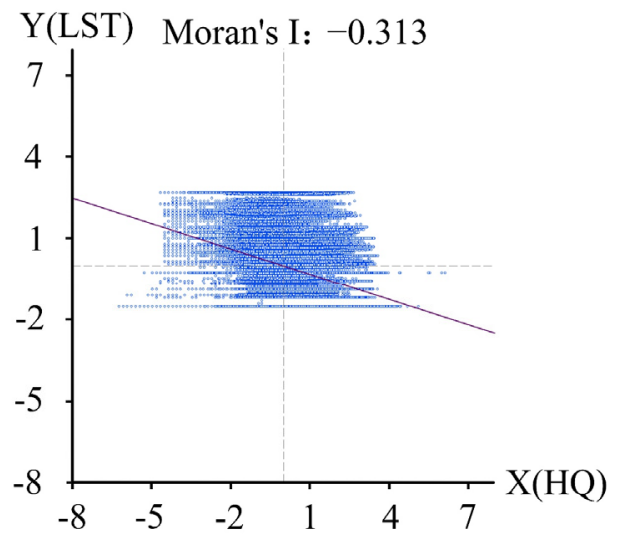

2010

Y(LST) Moran's I: 0.323

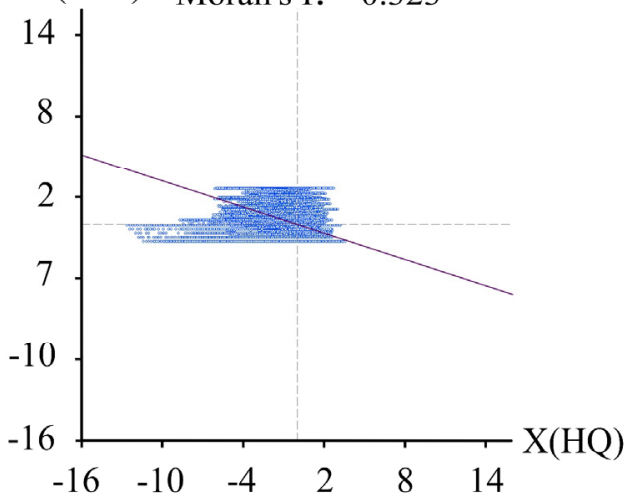

\section{5}

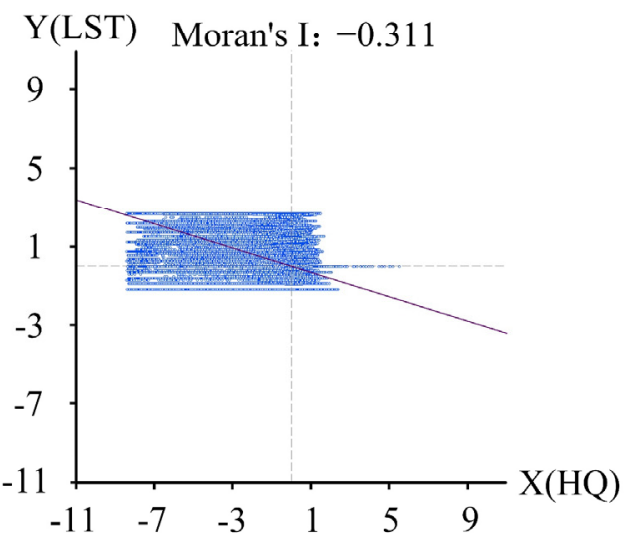

Figure 7. The Moran's I scatter diagram of LST and habitat quality during the different periods from 2000 to 2015.

The global Moran's I only represents the overall correlation trend of the two variables and cannot reflect the agglomeration differences in specific spatial locations. Therefore, the local Moran's I was further calculated, and the results (LST-habitat quality) were divided into four aggregation types: high-high (H-H), low-low (L-L), high-low (H-L), and low-high (L-H). The LISA (Local Indicators of Spatial Association) cluster map of LST and habitat quality clearly show the spatial agglomeration characteristics of regions that have passed the significance test (Figure 8). 

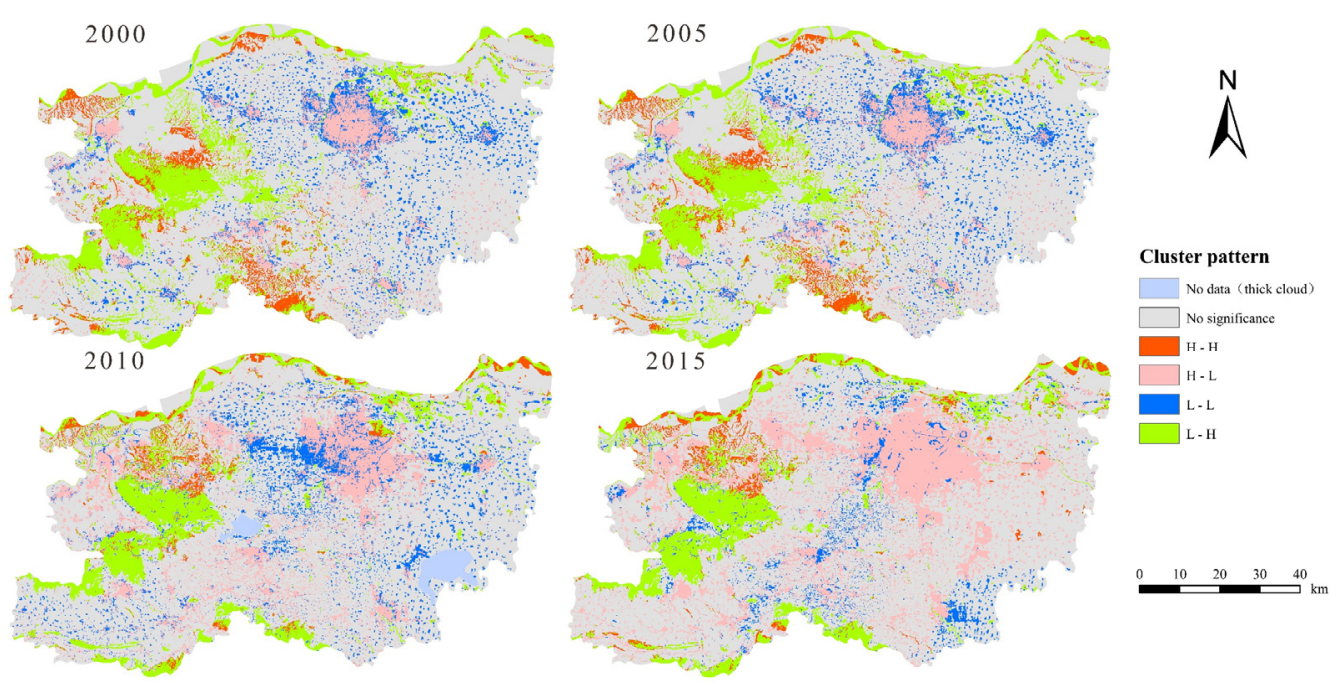

Figure 8. LISA cluster map of LST and habitat quality during the different periods from 2000-2015.

The H-H type was scattered mainly in the western and northern regions of the study area, showing a significant reduction trend from 2000 to 2015, indicating that the rise of a certain LST in some areas in the initial stage can promote the flow of energy and materials in the habitat, but the continuous high LST straightforwardly led to different degrees of structural confusion, dysfunction, and other degradation trends in different habitats. The $\mathrm{H}-\mathrm{L}$ type was mainly distributed in densely populated and actively built central urban areas, showing a continuous expansion trend, indicating that suburbanization of residential areas is bound to be accompanied by suburban urbanization. The gradual diffusion of manufacturing and industrial agglomeration centers from central urban areas to suburbs is the main reason for the rise of LST. The excessive LST destroys the structure and function of the original habitat. This has resulted in the decline of habitat quality.

The L-L type was mainly distributed in the urban-rural transition zone and small and medium-sized rural residential areas, showing a decreasing trend. The rural areas were dominated by cultivated land habitats in the initial stage of farming. Therefore, the traditional agricultural operation had little impact on the LST, the LST value remained at a low level, and the quality of cultivated land habitat itself was at a low level; thus, it presented a low-low agglomeration trend. However, with the development of mechanized farming technology, artificial heat source increases the LST, and the accumulation type has a great tendency to change to the H-L type.

The L-H type was mainly distributed in the western mountains and hills and the riparian areas of northern waters. It has remained stable in quantity and space for a long time, indicating that the LST in the natural environment was generally lower than that in the human activity area. It was suitable for the growth and reproduction of species.

The results show obvious differences in the spatial correlation of habitat quality and LST in Zhengzhou, and the differentiation results were also evolving with the development of Zhengzhou.

\section{Discussion}

From the perspective of LST, we analyzed the temporal and spatial differentiation of habitat quality characteristics. It reflects the gradient effect between habitat quality and LST, and reveals the agglomeration characteristics of the two in a specific spatial location.

According to the results of Section 4.2, we can speculate that the intensity and distribution of urban thermal environment is affected by changes in population aggregation, resource consumption, and industrial development, etc. In the initial stage (2000-2005), the rural population around Zhengzhou gathered in built-up areas, and the high temperature agglomerate in small areas, so the overall LST decreased. In the stage of rapid development (2005-2010), with more foreign population and their material demand, a large number 
of industrial zones had to be built around the built-up area, which were bound to be accompanied by the release of heat energy, so the overall LST rose. In the stage of stable construction (2010-2015), with the strengthening of energy conservation and emission reduction policy, the government was strictly guiding industry to reduce the use of fossil energy, restricting the use of coal and oil, and encouraging subsidies for the development of wind energy, so the overall LST dropped.

According to the results of Section 4.3, we can speculate that in 2000, with increasing construction and production activities, the LST changed suddenly, resulting in a tremendous impact on the quality of urban habitat. After 2010, with the city entering a period of stable development, the government increased the supervision of nature reserves and strictly controlled intensity of urban development. Moreover, the public had also been consciously advocating ecological environment protection and actively responding to global warming. Therefore, The LST gradually returned to the controllable range, which had a weaker impact on the quality of most habitats compared to 2000 and 2005. The prediction was consistent with the variation characteristics of habitat quality in response to LST in Figure 6.

It should be noted that there are still many other possible factors affecting the urban habitat quality, including LUCC, topographic features, meteorology, socio-economic condition, vegetation, etc. The LST is the one factor affecting habitat quality in the region that may interact with other ecological factors. In follow-up studies, the following should be considered: to take grid units of different scales as habitats, to introduce more potential factors in combination with observation stations, and to deeply study the spatio-temporal dynamic evolution law of urban habitat quality to provide a reference for the government to take more accurate ecological management and construction measures to protect urban habitats. In addition, although the LST is easy to obtain through remote sensing inversion, there are random errors in the instantaneous data, which may be affected by the weather and time of the day. As the LST inversion needs the thermal infrared information of ground objects, the shielding of cloudy weather will affect the results. There are also certain differences in the surface temperature during the day, such as evening and noon, and the acquisition time of the existing remote sensing images is not fixed. Further, we will try to set up some field meteorological stations to acquire LST measured data to correct the possible errors caused by both weather and time. In the future, in the construction of urban human settlements and biodiversity protection, we can start from the following aspects:

(1) Carrying out scientific urban planning and building design to reduce the area of the impervious layer. Building green low-carbon buildings to reduce carbon emission reduction in the whole life cycle of buildings is the most ecological and effective means to reduce the "urban heat island" effect and increase urban biodiversity. For example, roof greening can provide a good habitat for some animals, such as butterflies and bees, and provide a certain food source for some birds. It can also use its special habitat ex situ protection box to breed some endangered plant species and increase urban biodiversity. In addition, the city's wind circulation plays a significant role in improving the LST of the city [48]. The reasonable shape and structure model of urban buildings can form a favorable environment for wind circulation. Through the atmospheric circulation, the heat island can exchange with the air in the surrounding areas, to reduce the temperature of the city. Therefore, we can effectively arrange the plane and facade of the building, and the volume and height should be organically combined, so that the wind can form a circulation within a certain range. Furthermore, the layout of the living area, office area, commercial area, and industrial area in the city should be reasonably considered to build a multi-functional mixed urban system; particularly, the industrial area should vigorously develop new energy to slow down the heat accumulation.

(2) Building urban green infrastructure systems with stable energy cycles. As an important part of green infrastructure, vegetation can fully absorb the solar radiation [49]. It converts most of the radiant energy into chemical energy in photosynthesis, so as to transfer a large amount of heat energy, which promotes energy conversion and material 
circulation of the urban ecosystem [50,51]. More near natural habitats can be created through reasonable green infrastructure layout, increasing ventilation corridors, and reducing unnecessary hard environment to provide good living conditions for people to coexist harmoniously with other organisms.

(3) Developing new energy technologies. A large amount of man-made heat energy is one of the important factors in the rise of LST, such as the use of air-conditioning in summer, industrial exhaust gas, and automobile exhaust emissions. Therefore, it is necessary to reduce the use of nonrenewable energy, promote the use of new energy, and continue to develop new energy such as wind energy, solar energy, and other renewable energy sources for improving the urban habitat [52-54]. Among them, biomass energy has the advantage of being renewable, clean and low-carbon, and with an abundance of raw materials. The total amount of waste generated in Chinese cities every year is abundant. If it is not used rationally, it is easy to waste resources, even pollute the environment, and reduce the quality of urban habitat. Therefore, the development of biomass technology is particularly important. Currently, the bioenergy utilization technologies currently under development in China mainly include thermochemical conversion technology, biochemical conversion technology, biomass briquetting technology, etc. In addition, the use of geothermal technology is very common in some European countries, and we can use geothermal resources to serve construction. Through the development of ground source heat pump technology, the use of air conditioning in buildings can be greatly reduced.

(4) Optimizing the spatial pattern of biodiversity conservation according to local conditions. On the one hand, LST should be adjusted to reduce its negative effects on biological survival. On the other hand, the nature reserves should be optimized, and the protection and supervision of priority areas should be strengthened according to the life history, genes, physiological characteristics, and geographical scope of local organisms with regard to changes in LST $[55,56]$. For example, we can improve the ex situ conservation system of biodiversity and build ecological corridors that promote species migration and gene exchange, so as to solve the outstanding problems such as urban heat islands, fragmentation and isolated islands of natural habitat, and low ecological connectivity $[57,58]$. Moreover, sustainable utilization technologies of the biological resources at all levels and types of habitats should be deeply studied $[59,60]$.

\section{Conclusions}

Based on the analysis of the spatio-temporal differentiation characteristics of habitat quality in Zhengzhou from 2000 to 2015, the critical indicator of LST was introduced to study whether there is a gradient effect and spatial correlation between habitat quality and LST. The main conclusions are as follows:

(1) From 2000 to 2015, the urbanization of Zhengzhou was in a period of accelerated development. The mean value of habitat quality gradually decreased from 0.361 to 0.304 , and a large number of middle and middle-low level habitats (II and III) turned into low habitats (I), but the degradation trend slowed down in 2010. Spatially, middle-low level habitats (II) were the most widely distributed, mainly in the low-elevation plains in the east, and low-level habitats (I) were concentrated in the urban built-up areas; middle- and high-level habitats (III, IV, and V) were mainly distributed in the high-altitude western mountainous and hilly regions and northern waters.

(2) LST dropped slightly from 2000 to 2005, rose significantly in 2010, and dropped slightly again in 2015 . Spatially high gradients $(8,9,10)$ were distributed in the central urban area and the southern airport area, medium gradients $(5,6,7,8)$ were widely distributed, and low gradients $(1,2,3,4)$ were concentrated in the higher elevations of the western mountains and northern waters.

(3) Habitat quality in different periods showed different trends along the LST gradient. High values of habitat quality were concentrated in low gradients $(2,3,4)$. Low values were concentrated in high gradients $(8,9,10)$, indicating that a slightly lower LST can ensure habitat stability. The excessively high LST may have reduced surface runoff, water 
shortage, and other natural restrictive factors, resulting in the decline of the functional structure of the habitat and the ability to support the biological community.

(4) The global Moran's I of the four periods were $-0.430,-0.313,-0.323$, and -0.311 . Overall, there was a significant spatial negative correlation: the higher the LST, the lower the habitat quality. However, at different spatial locations, the distribution and agglomeration characteristics of LST and habitat quality can be divided into the following four types of agglomeration: the high-high type was scattered mainly in the western and northern regions of the study area; the high-low type was mainly distributed in densely populated and actively constructed central urban areas; the low-low type was mainly distributed in the urban-rural intersection and small- and medium-sized rural settlements; and the low-high type was mainly distributed in the western mountain hills and the northern waters and river banks.

(5) Combined with the research results and the existing policies of local authorities, we put forward the following suggestions to improve habitat and biodiversity: carrying out scientific urban planning and building design; building the urban green infrastructure systems with stable energy cycles; developing new energy technologies; and optimizing the spatial pattern of biodiversity conservation. Our innovative research has drawn some laws about the spatial correlation between Zhengzhou's habitat quality and LST, but it is relatively limited. More potential factors will be added in the follow-up research to explore the driving mechanism of urban habitat quality to provide systematic theoretical support for habitat and biodiversity protection in other similar cities.

Author Contributions: Conceptualization, Y.H. and E.X.; methodology, Y.H. and E.X.; software, E.X. and C.L.; validation, Y.H., E.X., G.K. and G.T.; formal analysis, Y.H. and E.X.; investigation, Y.H. and C.L.; resources, Y.H.; data curation, G.K.; writing-original draft preparation, Y.H. and G.K.; writing-review and editing, Y.H., E.X. and G.K.; visualization, C.L. and G.K.; supervision, G.K. and G.T.; project administration, G.T.; funding acquisition, G.T. All authors have read and agreed to the published version of the manuscript.

Funding: This study was supported by Urban-Rural Green Space Resources Control and Landscape Ecological Design Disciplinary Innovation and Talents Introduction Centre Program of Henan, China (GXJD006) and the Key Technology R\&D Program of Henan Province (212102310838), the Special Fund for Young Talents in Henan Agricultural University (30500930 and 30501053), the Youth Fund of Ministry of Education Laboratory for Earth Surface Processes of Peking University.

Data Availability Statement: The data presented in this study are available on request from the first author.

Acknowledgments: We would like to thank the International Joint Laboratory of Landscape Architecture for their support and Henan Agricultural University for their great help. We also thank the Institute of Geographical Sciences and Natural Resource Research, Chinese Academy of Sciences, and United States Geological Survey.

Conflicts of Interest: The authors declare no conflict of interest.

\section{References}

1. Di Febbraro, M.; Sallustio, L.; Vizzarri, M.; De Rosa, D.; De Lisio, L.; Loy, A.; Eichelberger, B.A.; Marchetti, M. Expert-Based and Correlative Models to Map Habitat Quality: Which Gives Better Support to Conservation Planning? Glob. Ecol. Conserv. 2018, 16, e00513. [CrossRef]

2. Mori, A.S.; Dee, L.E.; Gonzalez, A.; Ohashi, H.; Isbell, F. Biodiversity-Productivity Relationships Are Key to Nature-Based Climate Solutions. Nat. Clim. Chang. 2021, 11, 543-550. [CrossRef]

3. Lavergne, S.; Mouquet, N.; Thuiller, W.; Ronce, O. Biodiversity and Climate Change: Integrating Evolutionary and Ecological Responses of Species and Communities. Annu. Rev. Ecol. Evol. Syst. 2010, 41, 321-350. [CrossRef]

4. Hemanth Kumar, N.K.; Murali, M.; Girish, H.V.; Chandrashekar, S.; Amruthesh, K.N.; Sreenivasa, M.Y.; Jagannath, S. 2-Impact of Climate Change on Biodiversity and Shift in Major Biomes. In Global Climate Change; Singh, S., Singh, P., Rangabhashiyam, S., Srivastava, K.K., Eds.; Elsevier: Amsterdam, The Netherlands, 2021; pp. 33-44, ISBN 978-0-12-822928-6.

5. Nath, S.; Shyanti, R.K.; Nath, Y. 4-Influence of Anthropocene Climate Change on Biodiversity Loss in Different Ecosystems. In Global Climate Change; Singh, S., Singh, P., Rangabhashiyam, S., Srivastava, K.K., Eds.; Elsevier: Amsterdam, The Netherlands, 2021; pp. 63-78, ISBN 978-0-12-822928-6. 
6. $\quad$ Li, Z.-L.; Tang, B.-H.; Wu, H.; Ren, H.; Yan, G.; Wan, Z.; Trigo, I.F.; Sobrino, J.A. Satellite-Derived Land Surface Temperature: Current Status and Perspectives. Remote Sens. Environ. 2013, 131, 14-37. [CrossRef]

7. Gillespie, A.; Rokugawa, S.; Matsunaga, T.; Cothern, J.S.; Hook, S.; Kahle, A.B. A Temperature and Emissivity Separation Algorithm for Advanced Spaceborne Thermal Emission and Reflection Radiometer (ASTER) Images. IEEE Trans. Geosci. Remote Sens. 1998, 36, 1113-1126. [CrossRef]

8. Zhou, D.; Xiao, J.; Bonafoni, S.; Berger, C.; Deilami, K.; Zhou, Y.; Frolking, S.; Yao, R.; Qiao, Z.; Sobrino, J.A. Satellite Remote Sensing of Surface Urban Heat Islands: Progress, Challenges, and Perspectives. Remote Sens. 2019, 11, 48. [CrossRef]

9. Friedl, M.A. Forward and Inverse Modeling of Land Surface Energy Balance Using Surface Temperature Measurements. Remote Sens. Environ. 2002, 79, 344-354. [CrossRef]

10. Qi, Y.; Lian, X.; Wang, H.; Zhang, J.; Yang, R. Dynamic Mechanism between Human Activities and Ecosystem Services: A Case Study of Qinghai Lake Watershed, China. Ecol. Indic. 2020, 117, 106528. [CrossRef]

11. Rushing, C.S.; Royle, J.A.; Ziolkowski, D.J.; Pardieck, K.L. Migratory Behavior and Winter Geography Drive Differential Range Shifts of Eastern Birds in Response to Recent Climate Change. Proc. Natl. Acad. Sci. USA 2020, 117, 12897-12903. [CrossRef] [PubMed]

12. Johnson, M.D. Measuring Habitat Quality: A Review. Condor 2007, 109, 489-504. [CrossRef]

13. Lin, Y.-P.; Lin, W.-C.; Wang, Y.-C.; Lien, W.-Y.; Huang, T.; Hsu, C.-C.; Schmeller, D.S.; Crossman, N.D. Systematically Designating Conservation Areas for Protecting Habitat Quality and Multiple Ecosystem Services. Environ. Model. Softw. 2017, 90, 126-146. [CrossRef]

14. Tallis, H.; Lubchenco, J. Working Together: A Call for Inclusive Conservation. Nature 2014, 515, 27-28. [CrossRef] [PubMed]

15. Jill, B. Planetary Health: Protecting Nature to Protect Ourselves. Samuel Myers and Howard Frumkin (Eds). Int. J. Epidemiol. 2021, 50, 697-698. [CrossRef]

16. Seto, K.C.; Guneralp, B.; Hutyra, L. Global Forecasts of Urban Expansion to 2030 and Direct Impacts on Biodiversity and Carbon Pools. Proc. Natl. Acad. Sci. USA 2012, 109, 16083-16088. [CrossRef]

17. Kowarik, I. Novel Urban Ecosystems, Biodiversity, and Conservation. Environ. Pollut. 2011, 159, 1974-1983. [CrossRef] [PubMed]

18. Feest, A.; Aldred, T.D.; Jedamzik, K. Biodiversity Quality: A Paradigm for Biodiversity. Ecol. Indic. 2010, 10, 1077-1082. [CrossRef]

19. Magurran, A.E.; Baillie, S.R.; Buckland, S.T.; Dick, J.M.; Elston, D.A.; Scott, E.M.; Smith, R.I.; Somerfield, P.J.; Watt, A.D. Long-Term Datasets in Biodiversity Research and Monitoring: Assessing Change in Ecological Communities through Time. Trends Ecol. Evol. 2010, 25, 574-582. [CrossRef]

20. Sherrouse, B.C.; Semmens, D.J.; Clement, J.M. An Application of Social Values for Ecosystem Services (SolVES) to Three National Forests in Colorado and Wyoming. Ecol. Indic. 2014, 36, 68-79. [CrossRef]

21. Sharps, K.; Masante, D.; Thomas, A.; Jackson, B.; Redhead, J.; May, L.; Prosser, H.; Cosby, B.; Emmett, B.; Jones, L. Comparing Strengths and Weaknesses of Three Ecosystem Services Modelling Tools in a Diverse UK River Catchment. Sci. Total Environ. 2017, 584, 118-130. [CrossRef] [PubMed]

22. Huang, Z.; Bai, Y.; Alatalo, J.M.; Yang, Z. Mapping Biodiversity Conservation Priorities for Protected Areas: A Case Study in Xishuangbanna Tropical Area, China. Biol. Conserv. 2020, 249, 108741. [CrossRef]

23. Sohn, H.-J.; Kim, D.-H.; Kim, N.-Y.; Hong, J.-P.; Song, Y.-K. Evaluation indicators for the restoration of degraded urban ecosystems and the analysis of restoration performance. J. Korean Soc. Environ. Restor. Technol. 2019, 22, 97-114. [CrossRef]

24. Kija, H.K.; Ogutu, J.O.; Mangewa, L.J.; Bukombe, J.; Verones, F.; Graae, B.J.; Kideghesho, J.R.; Said, M.Y.; Nzunda, E.F. SpatioTemporal Changes in Wildlife Habitat Quality in the Greater Serengeti Ecosystem. Sustainability 2020, 12, 2440. [CrossRef]

25. Yu, W.; Ji, R.; Han, X.; Chen, L.; Feng, R.; Wu, J.; Zhang, Y. Evaluation of the Biodiversity Conservation Function in Liaohe Delta Wetland, Northeastern China. J. Meteorol. Res. 2020, 34, 798-805. [CrossRef]

26. Benez-Secanho, F.J.; Dwivedi, P. Analyzing the Provision of Ecosystem Services by Conservation Easements and Other Protected and Non-Protected Areas in the Upper Chattahoochee Watershed. Sci. Total Environ. 2020, 717, 137218. [CrossRef]

27. Rimal, B.; Sharma, R.; Kunwar, R.; Keshtkar, H.; Stork, N.E.; Rijal, S.; Rahman, S.A.; Baral, H. Effects of Land Use and Land Cover Change on Ecosystem Services in the Koshi River Basin, Eastern Nepal. Ecosyst. Serv. 2019, 38, 100963. [CrossRef]

28. Dai, L.; Li, S.; Lewis, B.J.; Wu, J.; Yu, D.; Zhou, W.; Zhou, L.; Wu, S. The Influence of Land Use Change on the Spatial-Temporal Variability of Habitat Quality between 1990 and 2010 in Northeast China. J. For. Res. 2019, 30, 2227-2236. [CrossRef]

29. Zhang, T.; Gao, Y.; Li, C.; Xie, Z.; Chang, Y.; Zhang, B. How Human Activity Has Changed the Regional Habitat Quality in an Eco-Economic Zone: Evidence from Poyang Lake Eco-Economic Zone, China. Int. J. Environ. Res. Public Health 2020, $17,6253$. [CrossRef] [PubMed]

30. Long, H.; Liu, Y.; Hou, X.; Li, T.; Li, Y. Effects of Land Use Transitions Due to Rapid Urbanization on Ecosystem Services: Implications for Urban Planning in the New Developing Area of China. Habitat Int. 2014, 44, 536-544. [CrossRef]

31. Zhu, C.; Zhang, X.; Zhou, M.; He, S.; Gan, M.; Yang, L.; Wang, K. Impacts of Urbanization and Landscape Pattern on Habitat Quality Using OLS and GWR Models in Hangzhou, China. Ecol. Indic. 2020, 117, 106654. [CrossRef]

32. Yohannes, H.; Soromessa, T.; Argaw, M.; Dewan, A. Spatio-Temporal Changes in Habitat Quality and Linkage with Landscape Characteristics in the Beressa Watershed, Blue Nile Basin of Ethiopian Highlands. J. Environ. Manag. 2021, 281, 111885. [CrossRef] [PubMed]

33. Wang, H.; Tang, L.; Qiu, Q.; Chen, H. Assessing the Impacts of Urban Expansion on Habitat Quality by Combining the Concepts of Land Use, Landscape, and Habitat in Two Urban Agglomerations in China. Sustainability 2020, 12, 4346. [CrossRef] 
34. Song, S.; Liu, Z.; He, C.; Lu, W. Evaluating the Effects of Urban Expansion on Natural Habitat Quality by Coupling Localized Shared Socioeconomic Pathways and the Land Use Scenario Dynamics-Urban Model. Ecol. Indic. 2020, 112, 106071. [CrossRef]

35. Nematollahi, S.; Fakheran, S.; Kienast, F.; Jafari, A. Application of InVEST Habitat Quality Module in Spatially Vulnerability Assessment of Natural Habitats (Case Study: Chaharmahal and Bakhtiari Province, Iran). Environ. Monit. Assess. 2020, $192,487$. [CrossRef] [PubMed]

36. Zhang, H.; Zhang, C.; Hu, T.; Zhang, M.; Ren, X.; Hou, L. Exploration of Roadway Factors and Habitat Quality Using InVEST. Transp. Res. Part D Transp. Environ. 2020,87, 102551. [CrossRef]

37. Zhang, H.B.; Liu, Y.Q.; Xu, Y.; Han, S.; Wang, J. Impacts of Spartina Alterniflora Expansion on Landscape Pattern and Habitat Quality: A Case Study in Yancheng Coastal Wetland, China. Appl. Ecol. Environ. Res. 2020, 18, 4669-4683. [CrossRef]

38. Liu, J.; Zhang, Z.; Xu, X.; Kuang, W.; Zhou, W.; Zhang, S.; Li, R.; Yan, C.; Yu, D.; Wu, S.; et al. Spatial Patterns and Driving Forces of Land Use Change in China during the Early 21st Century. J. Geogr. Sci. 2010, 20, 483-494. [CrossRef]

39. Xu, X.; Liu, J.; Zhang, S.; Li, R.; Yan, C.; Wu, S. China multi period land use and land cover remote sensing monitoring data set (CNLUCC). Data Regist. Publ. Syst. Resour. Environ. Sci. Data Cent. Acad. Sci. 2018. [CrossRef]

40. Nie, C.; Yang, J.; Huang, C. Assessing the Habitat Quality of Aquatic Environments in Urban Beijing. Procedia Environ. Sci. 2016, 36, 162-168. [CrossRef]

41. Lee, D.J.; Jeon, S.W. Estimating Changes in Habitat Quality through Land-Use Predictions: Case Study of Roe Deer (Capreolus Pygargus Tianschanicus) in Jeju Island. Sustainability 2020, 12, 123. [CrossRef]

42. Choudhary, A.; Deval, K.; Joshi, P.K. Study of Habitat Quality Assessment Using Geospatial Techniques in Keoladeo National Park, India. Environ. Sci. Pollut. Res. 2021, 28, 14105-14114. [CrossRef] [PubMed]

43. Li, X.; Yu, X.; Wu, K.; Feng, Z.; Liu, Y.; Li, X. Land-Use Zoning Management to Protecting the Regional Key Ecosystem Services: A Case Study in the City Belt along the Chaobai River, China. Sci. Total Environ. 2020, 24, 143167. [CrossRef] [PubMed]

44. Tomlinson, C.J.; Chapman, L.; Thornes, J.E.; Baker, C. Remote Sensing Land Surface Temperature for Meteorology and Climatology: A Review. Meteorol. Appl. 2011, 18, 296-306. [CrossRef]

45. Sobrino, J.A.; Jiménez-Muñoz, J.C.; Paolini, L. Land Surface Temperature Retrieval from LANDSAT TM 5. Remote Sens. Environ. 2004, 90, 434-440. [CrossRef]

46. Moran, P.A. Notes on Continuous Stochastic Phenomena. Biometrika 1950, 37, 17-23. [CrossRef] [PubMed]

47. Anselin, L. Local Indicators of Spatial Association-LISA. Geogr. Anal. 2010, 27, 93-115. [CrossRef]

48. Mills, G. Urban Climatology: History, Status and Prospects. Urban Clim. 2014, 10, 479-489. [CrossRef]

49. Hua, L.; Zhang, X.; Nie, Q.; Sun, F.; Tang, L. The Impacts of the Expansion of Urban Impervious Surfaces on Urban Heat Islands in a Coastal City in China. Sustainability 2020, 12, 475. [CrossRef]

50. Sturiale, L.; Scuderi, A. The Role of Green Infrastructures in Urban Planning for Climate Change Adaptation. Climate 2019, 7, 119. [CrossRef]

51. Kato, M.; Yoshizaki, S.; Hashida, S.; Lee, K.; Suzuki, H. The Evaluation of Tree Species of Urban Greening in Japan for Increasing the Bio-Diversity in Urban Area. J. Jpn. Soc. Reveg. Technol. 2016, 42, 3-8. [CrossRef]

52. Belaud, J.P.; Adoue, C.; Vialle, C.; Chorro, A.; Sablayrolles, C. A Circular Economy and Industrial Ecology Toolbox for Developing an Eco-Industrial Park: Perspectives from French Policy. Clean Technol. Environ. Policy 2019, 21, 967-985. [CrossRef]

53. Kardooni, R.; Yusoff, S.B.; Kari, F.B.; Moeenizadeh, L. Public Opinion on Renewable Energy Technologies and Climate Change in Peninsular Malaysia. Renew. Energy 2018, 116, 659-668. [CrossRef]

54. Qazi, A.; Hussain, F.; Rahim, N.A.B.D.; Hardaker, G.; Alghazzawi, D.; Shaban, K.; Haruna, K. Towards Sustainable Energy: A Systematic Review of Renewable Energy Sources, Technologies, and Public Opinions. IEEE Access 2019, 7, 63837-63851. [CrossRef]

55. Firake, D.M.; Lytan, D.; Behere, G.T. Bio-Diversity and Seasonal Activity of Arthropod Fauna in Brassicaceous Crop Ecosystems of Meghalaya, North East India. Mol. Entomol. 2013, 3, 18-22. [CrossRef]

56. Beninde, J.; Veith, M.; Hochkirch, A. Biodiversity in Cities Needs Space: A Meta-Analysis of Factors Determining Intra-Urban Biodiversity Variation. Ecol. Lett. 2015, 18, 581-592. [CrossRef]

57. Krosby, M.; Tewksbury, J.; Haddad, N.M.; Hoekstra, J. Ecological Connectivity for a Changing Climate. Conserv. Biol. 2010, 24, 1686-1689. [CrossRef] [PubMed]

58. Nor, A.N.M.; Corstanje, R.; Harris, J.A.; Grafius, D.R.; Siriwardena, G.M. Ecological Connectivity Networks in Rapidly Expanding Cities. Heliyon 2017, 3, e00325. [CrossRef] [PubMed]

59. Antar, M.; Lyu, D.; Nazari, M.; Shah, A.; Zhou, X.; Smith, D.L. Biomass for a Sustainable Bioeconomy: An Overview of World Biomass Production and Utilization. Renew. Sustain. Energy Rev. 2021, 139, 110691. [CrossRef]

60. Koukios, E.; Monteleone, M.; Carrondo, M.J.T.; Charalambous, A.; Girio, F.; Hernández, E.L.; Mannelli, S.; Parajó, J.C.; Polycarpou, P.; Zabaniotou, A. Targeting Sustainable Bioeconomy: A New Development Strategy for Southern European Countries. The Manifesto of the European Mezzogiorno. J. Clean. Prod. 2018, 172, 3931-3941. [CrossRef] 